\title{
Pengenalan Teknologi Hidroponik dengan System Wick (Sumbu) bagi Siswa SMA Negeri 2 Kabupaten Rejang Lebong Bengkulu
}

\section{Introduction of Hydroponic Technology with Wick System for Students of State High School 2 of Rejang Lebong Regency, Bengkulu}

Syaiful Eddy*
Dian Mutiara
Trimin Kartika
Conny Masitoh
Wahyu
Department of Biology, Universitas
PGRI Palembang, Palembang, South
Sumatra, Indonesia
*email: syaifuleddy@gmail.com
Kata Kunci
Hidroponik
Wick system
Rock wall
Keywords:
Hydroponics
Wick system
Rock wall
Received: June 2019
Accepted: August 2019
Published: September 2019

\begin{abstract}
Abstrak
Bertanam hidroponik saat ini menjadi alternatif sebagai usaha menyiasati keterbatasan lahan. Hidroponik dapat dilakukan dengan berbagai teknik, salah satunya dengan teknik yang sederhana yaitu menggunakan wick system (system sumbu) dengan memanfaatkan botol air mineral bekas daan arang sekam sebagai media tanam. Untuk mengenalkan teknologi hidroponik dengan wick system ini dilakukan pelatihan kepada siswa SMA Negeri 2 Rejang Lebong, dengan mengenalkan konsep dasar hidroponik, yaitu pembibitan, penyiapan nutrisi, pemeliharaan sampai pemanenan. Untuk menyemaian, bibit disemai di atas rock wall sebagai media penyemaian. Hasil kegiatan diperoleh hasil bahwa siswa terampil melaksanakan tahapan-tahapan kegiatan, sehingga dapat disimpulkan bahwa penerapan teknik bertanam secara hidroponik menggunakan wick system sangat baik untuk dikembangkan di kalangan siswa SMA, sebagai penerapan ilmu pengetahuan, teknologi dan kewirausahaan menghadapi dunia kerja, serta pemanfaatan barang bekas menjadi berdaya guna tinggi.
\end{abstract}

\begin{abstract}
Planting hydroponics is now an alternative as an effort to get around the limitations of the land. Hydroponics can be done with various techniques, one of which is a simple technique that is using the wick system by utilizing a bottle of used mineral water and husk charcoal as a planting medium. To introduce hydroponic technology with a wick system this training was conducted for students of Rejang Lebong 2 High School, by introducing the basic concepts of hydroponics, namely nursery, nutrition preparation, maintenance to harvesting. For seeding, seedlings are sown on Rockwall as a seeding medium. The results of the activity show that students are skilled at carrying out the stages of activities, so it can be concluded that the application of hydroponic farming techniques using the wick system is very good to be developed among high school students, as the application of science, technology, and entrepreneurship to the world of work, as well as the use of used goods, become highly efficient.
\end{abstract} (http://creativecommons.org/licenses/by-sa/4.0/). DOI: https://doi.org/10.33084/pengabdianmu.v4i2.804.

\section{PENDAHULUAN}

Hidroponik merupakan salah satu metode perbanyakan tanaman tanpa menggunakan media tanah. Biasanya metode ini digunakan untuk mengatasi kekurangan lahan tanam, terutama di kota-kota besar, dimana lahan pekarangan hampir tidak ada lagi (Hidayati et al., 2018).

Saat ini teknik penanaman secara hidroponik semakin berkembang, mulai dari sederhana dalam skala kecil hingga menggunakan teknik yang modern dalam skala besar (Roidah, 2014; Sharma et al., 2018). Bertanam dengan hidroponik memiliki beberapa keuntungan, 
antara lain tanaman lebih bersih, terutama sayursayuran, tanaman lebih mudah terkontrol, media dapat diganti dengan arang sekam, sabut kelapa bahkan rock wall (Indrawati et al., 2012). Hal terpenting adalah ketersediaan nutrisi, karena dengan nutrisi yang cukup, tanaman akan tumbuh subur, dengan masa panen yang lebih cepat. (Suhardjono \& Guntoro, 2013).

Dengan pengembangan teknologi, kombinasi sistem hidroponik dengan membran mampu mendayagunakan air, nutrisi, pestisida secara nyata lebih efisien (minimalis system) dibandingkan dengan kultur tanah (terutama untuk tanaman berumur pendek). Penggunaan sistem hidroponik tidak mengenal musim dan tidak memerlukan lahan yang luas dibandingkan dengan kultur tanah. Metode yang dipakai dalam bertanam hidroponik pun bermacam-macam (Mas'ud, 2009). Menurut Hidayati et al. (2017), budidaya secara hidroponik dapat dilakukan dalam ruang yang sempit, media tanam dapat diatur secara vertikal. Pada tanaman hidroponik juga dapat memberikan kesan design interior yang bagus dan menarik untuk digunakan sebagai hiasan di rumah. Banyak sebagian orang tidak mengetahui tentang apa itu hidroponik, dan bagaimana cara menanamnya.

Beberapa jenis hidroponik, yaitu Wick, Deep Water Culture (DWC), EBB dan Flow (Flood E Drain), Drip (recovery atau non-recovery), Nutrient Film Technique (NFT), dan Aeroponik. Ada ratusan variasi pada sistem hidroponik, tetapi semua metode hidroponik adalah variasi dan kombinasi dari enam jenis dasar. Dalam kegiatan ini akan digunakan jenis teknologi hidroponik sistem sumbu (wick), yang merupakan pengembangan dari sistem water culture (Puspasari et al., 2018). Sistem wick sangat efektif untuk skala rumah tangga, terutama untuk tanaman sayuran (Asmana et al., 2017).

Salah satu sentra penghasil sayuran adalah Kabupaten Rejang Lebong Provinsi Bengkulu. Sebagai sasaran pelatihan adalah siswa SMA Negeri 2 Rejang Lebong, yang merupakan salah satu SMA Unggulan di Kabupaten Rejang Lebong Bengkulu. SMA Negeri 2 Rejang Lebong telah memiliki prestasi dalam bidang kebersihan lingkungan dan penghargaan Adhiwiyata. Sekolah ini masih menjaga penghijauan sekolah dengan konsep penanaman alami, yakni di tanah langsung dan dalam pot dengan media tanah. Tentunya biaya yang digunakan dalam media tanah cukuplah besar. Untuk terus menjaga keasrian lingkungan dengan penghijauan yang asri, perlu dikenalkan teknologi hidroponik sederhana bagi siswa, melalui kegiatan pendampingan dan pelatihan teknologi hidroponik dengan wick system. Adapun kegiatan pengabdian ini bertujuan untuk memperkenalkan tentang Teknologi hidroponik dengan wick system tersebut kepada para siswa SMA Negeri 2 Rejang Lebong Bengkulu.

\section{METODOLOGI}

Pelatihan dilaksanakan selama satu bulan mulai tanggal 1 Maret sampai dengan 31 Maret 2019 dalam lima tahapan seperti ditampilkan pada Tabel I berikut:

Tabel I. Tahapan Kegiatan Pelatihan Hidroponik dengan Wick System di SMAN 2 Rejang Lebong

\begin{tabular}{ll}
\hline \multicolumn{1}{c}{ Tahapan } & \multicolumn{2}{c}{ Uraian Kegiatan } \\
\hline Persiapan & Tim pelaksana menyiapkan \\
dan & segala sesuatu untuk kegiatan \\
& PKM. Tim pelaksana akan \\
& memberikan sosialisasi berupa \\
& gambaran kegiatan PKM yang \\
& akan dilaksanakan kepada \\
& siswa. Kegiatan ini \\
& dilaksanakan dengan metode \\
& ceramah, tanya jawab dan \\
& praktek langsung. \\
Pembibitan & Pada tahap ini dilaksanakan \\
dan & dalam bentuk pelatihan. Materi \\
penyiapan & pelatihan yaitu mulai dari \\
nutrisi & penyiapan media, pembenihan \\
& hingga bibit tumbuh dan siap \\
& untuk ditanam serta \\
& pembuatan nutrisi \\
\hline
\end{tabular}




\begin{tabular}{ll}
\hline Penanaman & Tim pelaksana PKM akan \\
dan & mengecek perkembangan \\
pemeliharaan & penanaman hingga tanaman \\
& siap dipanen, melakukan dan \\
& checking lapangan. Pada tahap \\
& ini diharapkan siswa sudah \\
& paham dan terampil. \\
Panen & Siswa telah memahami tujuan \\
& dari penanaman dengan \\
& teknologi hidroponik \\
& sederhana ini menggunakan \\
& teknik wick system, dengan \\
& pemanenan tanaman yang \\
& telah matang. \\
& Tim pelaksana dan peserta \\
Monev & akan berdiskusi tentang sejauh \\
& mana tingkat keberhasilan \\
& program, kendala atau masalah \\
& yang dihadapai selama \\
& kegiatan berlangsung, dan \\
& saran serta tindak lanjut setelah \\
& kegiatan
\end{tabular}

\section{HASIL DAN PEMBAHASAN}

Berdasarkan tahapan-tahapan kegiatan yang telah dilaksanakan, siswa dapat mengerti prinsip dasar teknologi hidroponik sederhana dengan menggunakan teknik NFT. Tahapan pelaksaan menggunakan teknik hidroponik ini sudah sesuai dengan metode dasar menurut Hidayati et al. (2017), siswa telah menguasai teknik penyiapan media, pembenihan, penanaman, pembuatan dan penggunaan nutrisi, serta pemeliharaan tanaman sampai panen.

\section{Penyiapan Media Tanam}

Media tanam berupa arang sekam yang ditempatkan dalam botol air mineral bekas. Botol air mineral ukuran 1,5 L dipotong menjadi dua. Bagianbawah diisi nutrisi berupa AB Mix. Bagian atas yang merupakan tutup botol dilubangi, lalu diselipkan potongan kain flannel sepanjang $20 \mathrm{~cm}$, sebagai sumbu, lalu diletakkan terbalik di bertumpuk dengan bagian bawah. Bagian atas yang lalu diisi media tanam berupa arang sekam yang telah disterilkan (Gustia, 2013).

\section{Penyemaian}

Media tanam yang digunakan menggunakan rockwool. Bibit tanaman terlebih dahulu disemai dalam rockwool hingga muncul 2 helai daun. Rockwool adalah bahan non-organik yang dibuat dengan cara meniupkan udara atau uap ke dalam batuan yang dilelehkan. Hasilnya adalah sejenis fiber yang memiliki rongga-rongga dengan diameter umumnya antara 6-10 $\mu \mathrm{m}$. Rockwool dipotong dengan ukuran menyesuaikan lebar talang, kemudian dibuat lubang tanam dengan ukuran $2 \times 2$ $\mathrm{cm}$. Selanjutnya rockwool diberi air hingga basah. Benih diletakan dalam lubang tanam, masingmasing lubang tanam 1 buah benih (Sesanti \& Rismanto, 2016).

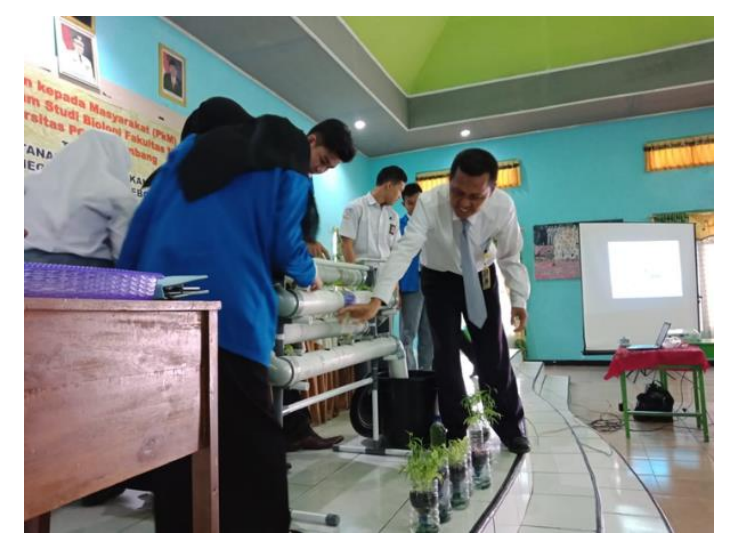

Gambar 1. Teknik pemeliharaan tanaman benih pada media

\section{Penyiapan Nutrisi}

Rasio nutrisi $\mathrm{AB}$ mix pada sistem NFT adalah $5 \mathrm{ml}$ larutan stok A dan $5 \mathrm{ml}$ larutan stok B untuk $1 \mathrm{~L}$ air. Pembuatan larutan nutrisi AB Mix dilakukan dengan cara melarutkan $\mathrm{AB}$ mix A (83 g) dan AB mix B (83 g) masing-masing ke dalam $500 \mathrm{~mL}$ air, selanjutnya kedua larutan tersebut dicampurkan ke dalam $100 \mathrm{~L}$ air kemudian diaduk hingga tercampur rata, nutrisi ini disimpan dalam ember plastik (Mas'ud, 2009).

\section{Pindah Tanam}

Kegiatan pindah tanam pada sistem hidroponik NFT dilakukan dengan cara memotong rockwool yang 
berisi bibit dengan ukuran $2 \times 2 \mathrm{~cm}$, selanjutnya masing masing kubus rockwool diletakan dalam gelas air mineral kemudian dimasukkan ke dalam media tanam (Nainggolan \& Ginting, 2019).

\section{Pemeliharaan}

\section{a. Pemberian Nutrisi}

Nutrisi diberikan setiap 1 minggu sekali larutan nutrisi dicek nilai EC dan $\mathrm{pH}$ nya. Jika nilai EC turun maka tambahkan nutrisi dalam larutan, sebaliknya jika nilai EC tinggi, tambahkan air ke dalam larutan. Derajat keasaman air $(\mathrm{pH})$ yang digunakan adalah 6,5-7. Nilai $\mathrm{pH}$ diukur dengan menggunakan $\mathrm{pH}$ meter. Jika nilai $\mathrm{pH}$ turun tambahkan $\mathrm{KOH}$ pada larutan, dan jika nilai $\mathrm{pH}$ naik tambahkan $\mathrm{HCl}$ hingga $\mathrm{pH}$ menjadi 6,5-7. Jika air di bagian bawah botol habis, segera ditambahkan dengan mengukur $\mathrm{pH}$ dan nutrisinya, agar tanaman tidak menjadi kering.

b. Pengendalian Hama dan Penyakit

Pengendalian hama dan penyakit dilakukan secara manual, dengan cara mengambil hama yang menyerang tanaman. Apabila tanaman pakchoi terserang penyakit, sebaiknya segera dibuang, untuk mencegah terjadinya penularan ke tanaman lain

c. Panen

Panen dilakukan saat tanaman tumbuh sempurna dengan cara mencabut tanaman satu persatu.

Sistem hidroponik merupakan salah satu cara menghasilkan produk tanaman terutama komoditas sayuran yang berkualitas tinggi secara berkelanjutan, sangat cocok untuk kawasan Kabupaten Rejang Lebong yang terkenal sebagai sentra penghasil sayur mayur. Teknik sistem hidroponik dapat dibedakan menjadi beberapa jenis berdasarkan cara pemberian nutrisi. Sistem sumbu (wick system), merupakan contoh teknologi sistem hidroponik yang sederhana, mudah dibuat, murah dan minim mengakibatkan pembusukan tanaman. Keadaan ini yang menjadi landasan bahwa teknologi bercocok tanam dengan sistem hidroponik dapat diterapkan dalam masyarakat dan diharapkan dapat meningkatkan produksi bahan pangan terutama komoditas sayur-sayuran skala kecil. Biaya yang digunakan sangat sedikit, karena memanfaatkan botol bekas air mineral (Yuarini et al., 2015).

Sistem kultur secara hidroponik ini menerapkan metode penanaman tanaman tanpa menggunakan media berupa tanah, sehingga, budidaya tanaman dengan metode ini tidak memerlukan lahan yang luas, cocok sebagai kegiatan wira usaha siswa sekolah dan rumah tangga. Selain itu, keuntungan dari penggunaan sistem ini dapat menghasilkan kuantitas dan kualitas produksi yang lebih tinggi dan bersih. Nutrisi yang digunakan dalam budidaya dengan sistem hidroponik adalah nutrisi $A B$ mix. Nutrisi $A B$ Mix mengandung 16 unsur hara esensial yang diperlukan tanaman, dari 16 unsur tersebut 6 diantaranya diperlukan dalam jumlah banyak (makro) yaitu N, $\mathrm{P}, \mathrm{K}, \mathrm{Ca}, \mathrm{Mg}$, S, dan 10 unsur diperlukan dalam jumlah sedikit (mikro) yaitu $\mathrm{Fe}, \mathrm{Mn}, \mathrm{Bo}, \mathrm{Cu}, \mathrm{Zn}$, $\mathrm{Mo}, \mathrm{Cl}, \mathrm{Si}$, Na dan $\mathrm{Co}$. Nutrisi AB mix adalah nutrisi yang digunakan dibagi menjadi dua stok yaitu stok $\mathrm{A}$ dan stok B. Stok A berisi senyawa yang mengan di Ca, sedangkan Stok B berisi senyawa yang mengandung sulfat dan fosfat (Wahyuningsih et al., 2016).

Meskipun penggunaan teknik wick system masih dalam skala kecil, metode ini memiliki nilai estetika yang tinggi, sebagai hiasan, dan juga sangat mudah memantaunya. Penerapan sistem bertanam hidroponik dengan menggunakan system ini sangat baik dilakukan bagi siswa, sebagai pengembangan ipteks (Natalia et al., 2017). Dengan mengkombinasikan antara materi pembelajaran IPA dan kewirausahaan sebagai modal dasar menghadapi dunia kerja. Siswa SMA Negeri 2 Rejang 
Lebong telah terampil melakukan kegiatan ini. Selama 3 minggu pelatihan, tanaman telah tumbuh dengan baik, siap dipanen. Hasil panen akan dikombinasikan dengan pelajaran kewirausahaan, dimana siswa akan memasarkan hasil bertanam hidroponik dengan wick system.

\section{KESIMPULAN}

Berdasarkan hasil pelatihan yang telah dilaksanakan, dapat disimpulkan bahwa penerapan teknik bertanam secara hidroponik menggunakan wick system sangat baik untuk dikembangkan di kalangan siswa SMA, sebagai penerapan ilmu pengetahuan, teknologi dan kewirausahaan menghadapi dunia kerja, dan sebagai usaha pemanfaatan barang bekas menjadi berdaya guna dan bernilai ekonomis tinggi.

\section{UCAPAN TERIMA KASIH}

Dalam kesempatan ini ucapan terima kasih kami tujukan kepada Rektor Universitas PGRI Palembang yang telah mendukung kegiatan ini, baik secara moril dan materil. Juga kepada Kepala SMA Negeri 2 Rejang Lebong beserta seluruh pegawai dan siswa, yang mendukung penuh pelaksanaan kegiatan Tri Darma Perguruan Tinggi bagi Dosen Program Studi Biologi Fakultas MIPA Universitas PGRI Palembang.

\section{REFERENSI}

Asmana, M.S., Abdullah, S.H., Putra, G.M.D. 2017. Analisis Keseragaman Aspek Fertigasi pada Desain Sistem Hidroponik dengan Perlakuan Kemiringan Talang. Jurnal Ilmiah Rekayasa Pertanian dan Biosistem. 5(1):303-315. https://doi.org/10.29303/jrpb.v5i1.41

Gustia, H. 2013. Pengaruh Penambahan Sekam Bakar pada Media Tanam terhadap Pertumbuhan dan Produksi Tanaman Sawi (Brassica juncea L.). Jurnal Widya Kesehatan Kopertis Wilayah III Jakarta. 1(1):12-17.
Hidayati, N., Rosawanti, P., Arfianto, F., Hanafi, N. 2018. Pemanfaatan Lahan Sempit untuk Budidaya Sayuran dengan Sistem Vertikultur. PengabdianMu: Jurnal Ilmiah Pengabdian kepada Masyarakat. $\quad 3(1): 40-46$. https://doi.org/10.33084/pengabdianmu.v3i 1.28

Hidayati, N., Rosawanti, P., Yusuf, F., Hanafi, N. 2017. Kajian Penggunaan Nutrisi Anorganik terhadap Pertumbuhan Kangkung (Ipomoea reptans Poir) Hidroponik Sistem Wick. Daun: Jurnal Ilmiah Pertanian dan Kehutanan. 4(2):7581. https://doi.org/10.33084/daun.v4i2.81

Indrawati, R., Indradewa, D., Utami, S.N.H. 2012. Pengaruh Komposisi Media dan Kadar Nutrisi Hidroponik terhadap Pertumbuhan dan Hasil Tomat (Lycopersicon esculentum Mill.). Vegetalika. 1(3):1-11. https:/ / doi.org/10.22146/veg.1361

Mas'ud, H. 2009. Sistem Hidroponik dengan Nutrisi dan Media Tanam Berbeda terhadap Pertumbuhan dan Hasil Selada. Media Litbang Sulawesi Tengah. 2(2):131-136.

Nainggolan, F.S., Ginting, M. 2019. Rancangan Sistem Irigasi Hidroponik NFT (Nutrient Film Technique) pada Budidaya Tanaman Pakcoy (Brassica rapa L.). Jurnal Teknik Sipil. 8(1):1-11.

Natalia, C., Kusumarini, Y., Poillot, J.K. 2017. Perancangan Interior Fasilitas Edukasi Hidroponik di Surabaya. Intra. 5(2):97-106.

Puspasari, I., Triwidyastuti, Y., Harianto, H. 2018. Otomasi Sistem Hidroponik Wick Terintegrasi pada Pembibitan Tomat Ceri. JNTETI (Jurnal Nasional Teknik Elektro dan Teknologi Informasi). 7(1):97-104.

http://dx.doi.org/10.22146/jnteti.v7i1.406

Roidah, I.S. 2014. Pemanfaatan Lahan dengan Menggunakan Sistem Hidroponik. Bonorowo: Jurnal Universitas Tulungagung. 1(2):43-50.

Sesanti, R.N., Sismanto. 2016. Pertumbuhan dan Hasil Pakchoi (Brasicca rapa L.) pada Dua Sistem Hidroponik dan Empat Jenis Nutrisi. Inovasi Pembangunan : Jurnal Kelitbangan.4(1):1-9.

Sharma, N., Acharya, S., Kumar, K., Singh, N., Chaurasia, O.P. 2018. Hydroponics as an advanced technique for vegetableproduction: An overview. Journal of Soil and Water Conservation. 
17(4):364-371.https://doi.org/10.5958/2455-

7145.2018.00056.5

Suhardjono, H. \& Guntoro, W. 2013. Pengaruh Komposisi Nutrisi Hidroponik dan Varietas terhadap Pertumbuhan dan Hasil Tanaman Pakchoy (Brassica chinensis L.) yang Ditanam secara Hidroponik. Agritrop: Jurnal Ilmu-Ilmu Pertanian (Journal of Agricultural Science). 11(1):73-77.

http://dx.doi.org/10.32528/agr.v11i1.673

Wahyuningsih, A., Fajriani, S., Aini, N. 2016. Komposisi Nutrisi dan Media Tanam terhadap Pertumbuhan dan Hasil Tanaman Pakcoy (Brassica rapa L.) Sistem hidroponik. Jurnal Produksi Tanaman. 4(8):595-601.

Yuarini, D.A.A., Satriawan, I.K., Suardi, I.D.P.O. 2015. Strategi Peningkatan Kualitas Produk Sayuran Segar Organik pada CV. Golden Leaf Farm Bali. Jurnal Manajemen Agribisnis. 3(2):93-109. 